\title{
Critical Factors Influencing the Intention to Adopt m-Government Services by the Elderly
}

\author{
Md. Shamim Talukder, Huazhong University of Science and Technology, Wuhan, China \\ Raymond Chiong, The University of Newcastle, Callaghan, Australia \& Fuzhou University, Fuzhou, China \\ Brian Corbitt, RMIT University, Melbourne, Australia \\ Yukun Bao, Huazhong University of Science and Technology, Wuhan, China
}

\begin{abstract}
While the elderly population is growing rapidly, acceptance and use of m-government services by them are far below expectation. Previous studies on acceptance and use of m-government services have predominantly focused on younger citizens with skills and experience of information technologies. Drawing upon the dual factor model, this study investigates the enablers and inhibitors of the elderly's m-government service adoption behavior. Four constructs from the unified theory of acceptance and use of technology (UTAUT), namely, performance expectancy, effort expectancy, facilitating conditions, social influence; and self-actualization are treated as enablers, while user resistance to change, technology anxiety, and declining physiological conditions are regarded as inhibitors. Results show that adoption of m-government by the elderly is significantly influenced by all tested enablers and inhibitors, except for social influence. This study contributes by providing an integrative model of technology acceptance for the elderly along with practical implications for policy makers.
\end{abstract}

\section{KEYWORDS}

Bangladesh, Developing Countries, Dual Factor Model, The Elderly, M-Government, UTAUT

\section{INTRODUCTION}

Population aging has become a major concern for governments worldwide. At present, approximately $11 \%$ of the world's population is aged 60 years and over, but this proportion is projected to increase to about $16.5 \%$ by 2030 (UN-DESA, 2017). Due to diminishing sensory input, cognitive dysfunction, disability, and impaired physiologic reserve, elderly people need personalized services and support from their government regarding healthcare, emergency contact, or power of attorney (Turner et al., 2018). Accordingly, the provision of efficient and effective delivery of these fundamental services to the elderly has become increasingly critical. The phenomenon of population aging is not limited to developed countries. Low- and middle- income countries are estimated to be more likely to bear 
much of this growth. Bangladesh, for example, has more than 13 million of its population over 60 years of age (Bangladesh Bureau of Statistics, 2017).

Mobile government ( $\mathrm{m}$-Government) services can provide better access for the elderly. m-government expands service delivery, improves levels of information sharing, provides precision and personalization in targeting users (such as the elderly), helps deliver content with greater cost optimization, and promotes stronger digital equality (Ahmad \& Khalid, 2017; Hung, Chang, \& Kuo, 2013). m-Government can also considerably improve support for the elderly, as physical presence or waiting at government institutions is no longer necessary, while active participation in politics and in other decision-making processes become more accessible (Choudrie, Alfalah, \& Spencer, 2017). However, there are issues regarding the acceptance and adoption of $\mathrm{m}$-Government services by the elderly. It is widely accepted that elderly people are relatively less skillful at using mobile technologies, and also have less experience in using them (Deng, Mo, \& Liu, 2014). They also do not show as much enthusiasm for adopting new technologies as the younger generation do, due to age-related vulnerability (Bao, Hoque, \& Wang, 2017).

To understand the issues related to m-Government service adoption, we need to consider not only the benefits brought by the services but also barriers inhibiting the adoption behavior. Past studies along this line of research have focused predominantly on m-Government adoption related to technical and non-technical barriers (Al-Hadidi \& Rezgui, 2010), organizational culture (Hussain \& Imran, 2015), roles of social networks (Tscherning \& Mathiassen, 2010), service quality perspectives (Al-Hubaishi et al., 2017), and trust, security or privacy issues (Liu et al., 2014; Susanto \& Goodwin, 2011; Wang, 2014). It is worth pointing out that researchers have paid more attention to the benefits of m-Government services than on the barriers (Ahmad \& Khalid, 2017; Talukder, Shen, Hossain Talukder, \& Bao, 2019). In addition, existing studies have primarily targeted the younger generation, such as middle-aged professionals or students who are relatively healthier, more sociable and active (Abdelghaffar \& Magdy, 2012; Liu et al., 2014).

To fill the above discussed research gaps, we draw upon a dual factor model of technology adoption proposed by Cenfetelli (2004) to investigate both the enablers and inhibitors of m-Government acceptance behavior among the elderly (i.e., those 60 years of age or older). Four constructs from the Unified Theory of Acceptance and Use of Technology (UTAUT), namely performance expectancy, effort expectancy, facilitating conditions, and social influence; and self-actualization are treated as enablers, while users' resistance to change, technology anxiety, and declining physiological conditions are regarded as the inhibitors. Bangladesh is used as a case study, however, our findings should be applicable to other developing countries of a similar nature. The findings of this study will contribute towards understanding the elderly's adoption of m-Government services. Additionally, we discuss the generalizability of our results as a whole.

\section{RESEARCH MODEL AND HYPOTHESIS DEVELOPMENT}

\subsection{Research Model}

The dual factor model of technology acceptance suggests that users' intention to adopt a technology is influenced both by the enablers and the inhibitors (Cenfetelli, 2004). According to Cenfetelli (2004) "the enablers refer to the factors which enhance usage when they are present, but at the same time, do not necessarily hurt usage when they are not available; in contrast, the inhibitors refer to the factors that hurt usage when they are present, but do not necessarily enhance usage when they are not available". Thus, the enablers and the inhibitors affect the technology adoption intention positively and negatively, respectively. In some cases, inhibitors not only directly influence technology adoption, but also indirectly influence technology adoption via enablers (Guo, Sun, Wang, Peng, \& Yan, 2013).

In this research context, a number of enablers of technology acceptance have been studied widely by applying a range of alternative theories and models. The concept of individual technology acceptance 
was introduced into the information systems literature by Davis (1989), with his technology acceptance model (TAM) and has since been subject to subsequent theory development, e.g., (Venkatesh \& Davis, 2000). Novel theories that are partially based on the TAM have been developed to explain individual technology usage behavior. The UTAUT, derived from Venkatesh, Morris, Davis, and Davis (2003), combines constructs from eight different competing theoretical models including the TAM. The authors present evidence that the model provides the best explanation compared to other models. The UTAUT theorized four key constructs: effort expectancy (EE), performance expectancy (PE), social influence (SI) and facilitating conditions (FC), as the main enablers of behavioral intentions (BI).

When performance expectancy and effort expectancy are present, users' m-Government service adoption behavior will be facilitated. The UTAUT framework allows researchers to examine which determinants affect information technology (IT) adoption surrounding government service offerings, taking social and several other facilitating factors into consideration (Saxena, 2017; Zuiderwijk, Janssen, \& Dwivedi, 2015). Social factors such as the elderly's behavior towards m-Government services as well as positive influence from and interaction between the elderly are highly relevant for the acceptance and use of $\mathrm{m}$-Government services. Likewise, facilitating conditions such as training programs, organizational and technological infrastructure, and availability of relevant resources for the use of m-Government systems are some of the mechanisms by which a government can positively influence elderly users' attitude towards and usage of the m-Government system (Ahmad \& Khalid, 2017; Talukder, Shen, et al., 2019).

On the other hand, self-actualization is an important enabler as it offers the intrinsic motivation to become everything that one is capable of becoming in life (Phang et al., 2006). It is associated with achieving a sense of fulfillment that gives motivation to older adults to explore new technologies and learn new skills (Heylighen, 1992). Thus, the constructs of the UTAUT model and self-actualization are the most suitable enablers to investigate $\mathrm{m}$-Government services adoption from the elderly.

Although the enablers have received much support in this context, it is equally necessary to investigate the inhibitors to understand the dark side of technology acceptance (i.e. m-Government) (Bhattacherjee \& Hikmet, 2007). In this study, three particular characteristics of elderly users, namely resistance to change, technology anxiety and declining physiological conditions are examined as inhibitors. First, resistance to change captures the elderly users' aversion to change. It reflects the pattern of how elderly users respond to changes induced by the usage of new technology (Guo et al., 2013). Elderly users have been found to have high propensity to resist changes (Hoque \& Sorwar, 2017). Because change in lifestyle follows the use of new technologies, the elderly's reaction to said change will also influence their intention to adopt the new technology (Xue et al., 2012). Secondly, technology anxiety in the elderly is often associated with self-imposed barriers and low self-efficacy in IT skills, leading to fear of technology and lack of interest and motivation (Turner, Turner, \& Van de Walle, 2007). Many studies about the elderly have argued that technology anxiety is one of the major barriers to adopting innovations (Hoque \& Sorwar, 2017; Phang et al., 2006). Thirdly, 'declining physiological conditions' refers to the acceptance of physical difficulties of vision, hearing, and motion that may be faced in everyday life (Xue et al., 2012). This acceptance can serve as internal controls or inhibiting conditions that might help decrease the elderly's use of $\mathrm{m}$-government services (Phang et al., 2006). Therefore, these three constructs capture the technology and personality-related dispositions of elderly users' when adopting m-government services, and should thus be included in the research model.

Our extended research model is shown in Figure 1. As can be seen from Figure 1, performance expectancy, effort expectancy, social influence, facilitating conditions, and resistance to change are taken as direct antecedents of behavioral intention; whereas anxiety, psychological conditions, and selfactualization are the antecedents of performance expectancy and effort expectancy. The antecedents of performance expectancy and effort expectancy are included to bridge the various individual traits, controllable interventions, and/or situational constraints impinging on behavior and individuals' 


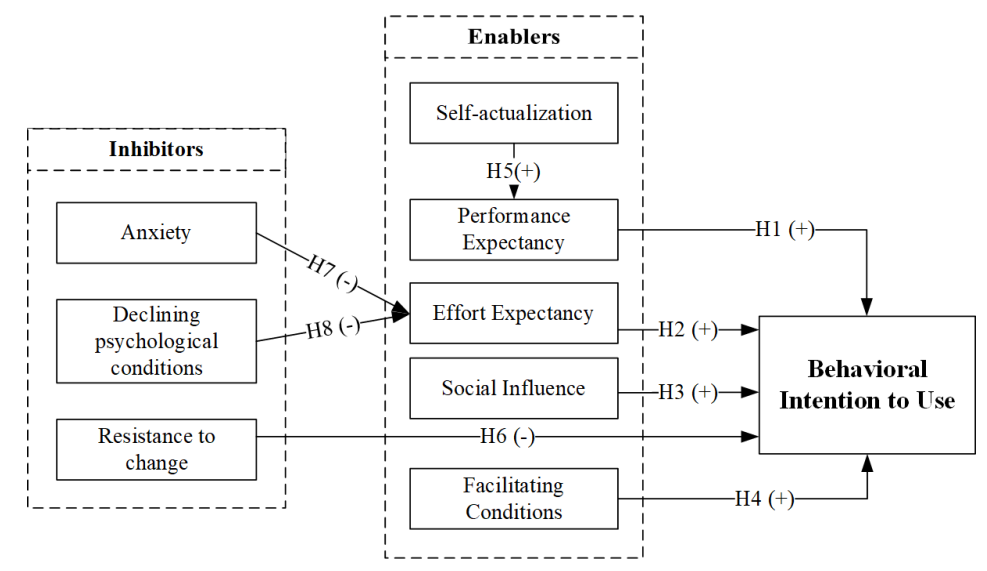

perceptions of the technology (Davis, Bagozzi, \& Warshaw, 1989; Phang et al., 2006). In the next section, we will discuss the development of hypotheses based on these antecedents.

\subsection{Hypothesis Development}

\subsubsection{The Impacts of Enablers}

\subsubsection{Performance Expectancy and Effort Expectancy}

Performance expectancy is an individual's belief that an information system (IS) will help him/her improve their work performance (Venkatesh et al., 2003). It refers to the degree to which the elderly believe that using the $\mathrm{m}$-Government services will provide timely, personalized information and services in an easier and more convenient manner; and also improve their efficiency and help them complete their tasks anytime and anywhere (Ahmad \& Khalid, 2017; Sultan, Naif Radi, Rakibul, $\&$ Fahd, 2018). A review of the factors influencing the elderly's acceptance of public services found performance expectancy to be the main predictor of acceptance (Choudrie et al., 2017). Higher performance expectancy of m-Government services by the elderly, such as perceived better management of their work, better access to public services, and improving quality of life in general, are expected to positively affect their intention to use those services.

Effort expectancy is defined as the degree of ease of use of the system (Venkatesh et al., 2003). Particularly during the initial use of technology, such as the acceptance of an innovation, the level of ease associated with using that technology strongly affects the acceptance behavior. As m-Government is still relatively new to the elderly, it is therefore important to determine if they perceive m-Government as being useful, easy to learn, or difficult to use, and whether this perception will lead to their adoption decisions. Past studies have suggested that effort expectancy strongly influences the users' intention to use innovative technologies (Ikram Ullah, Yugang, Zahid, Safeer Ullah, \& Abdul, 2018; Talukder, Chiong, Bao, \& Hayat Malik, 2019).

Based on the above discussion, we posit that:

H1: Performance expectancy (PE) has a positive impact on the elderly's intention to use m-Government services.

H2: Effort expectancy (EE) has a positive impact on the elderly's intention to use m-Government services. 


\subsubsection{Social Influence}

Social influence is the degree to which an individual perceives that important people in his/ her social circle champion the use of a new technology (Chong, Darmawan, Ooi, \& Lin, 2010). Besides the opinions of experts and their superiors, friends, family, and colleagues can all influence an individual's decision to adopt new technologies (Irani, Elliman, \& Jackson, 2007; Tsu Wei, Marthandan, Yee-Loong Chong, Ooi, \& Arumugam, 2009). During the initial adoption phase when they have little or no experience of the related innovation, their decisions are greatly influenced by the opinions in their social circle (Teo \& Pok, 2003a). Mass communication media such as the Internet, newspapers, television, radio, and magazines can also shape the individual's attitude towards the use of m-Government services. In most Asian countries, including Bangladesh, where the elderly typically live in joint families and under the care of their children, their children also play a crucial role in the adoption of such services. Therefore, the following hypothesis can be proposed:

H3: Social influence (SI) has a positive impact on the elderly's intention to use m-Government services.

\subsubsection{Facilitating Conditions}

Facilitating conditions, defined as the degree to which an individual believes that devices and infrastructure are available for using a technology (Venkatesh et al., 2003), are related to managing resources and sharing knowledge with the elderly to facilitate their use of m-Government systems. Owing to their relative unfamiliarity with new technologies, the elderly also require more support and facilitating conditions than other age segments of the population to access and use IT services, including m-Government services (Sintonen \& Immonen, 2013). Here, it is assumed that facilitating conditions can assist the elderly to use $\mathrm{m}$-Government services by providing necessary resources, knowledge, and support. Thus, the following hypothesis is postulated.

H4: Facilitating conditions (FC) have a positive impact on the elderly's intention to use m-Government services.

\subsubsection{Self-Actualization}

Self-actualization is important, as it offers the intrinsic motivation to become everything that one is capable of becoming in life (Maslow, Frager, Fadiman, McReynolds, \& Cox, 1970). It is associated with achieving a sense of fulfillment, seeking personal growth, and realizing personal potential (Phang et al., 2006). Higher self-actualization motivation makes people open to new experiences and to learning new ideas and skills (Heylighen, 1992). In this study, it is assumed that learning and using $\mathrm{m}$-Government systems might be an opportunity for the elderly to achieve a sense of accomplishment or self-actualization. Self-actualization is likely to develop the perception of m-Government services as useful tools to access and use public services. A reasonable number of prior studies have also reported that self-actualization can increase the usefulness of the system, particularly during the final stages of life (Conci, Pianesi, \& Zancanaro, 2009; Phang et al., 2006). Based on the above discussion, we propose the following hypothesis:

H5: Self-actualization (SA) has a positive impact on performance expectancy towards intention to use m-Government services. 


\subsubsection{The Impacts of Inhibitors}

\subsubsection{Resistance to Change}

In the IS literature, resistance to change refers to the adverse reaction of users to the proposed change (Hirschheim \& Newman, 1988). Resistance to change is considered to be one of the most important factors impeding the adoption of technology (Lallmahomed, Lallmahomed, \& Lallmahomed, 2017), and is responsible for the failure of some new systems and services (Dwivedi et al., 2015). It has also been identified as a major factor that reduces the propensity of potential users to adopt mobile technology related services like m-health and m-Government (Guo et al., 2013; Hoque \& Sorwar, 2017). The elderly's adoption of new technology like m-Government has been consistently hindered by resistance to change (Zickuhr \& Madden, 2012). In this study, resistance to change is defined as the elderly's opposition to switching from traditional government systems to innovative m-Government services. Therefore, we propose the following hypothesis:

H6: Resistance to change (RC) has a negative impact on the elderly's intention to use m-Government services.

\subsubsection{Technology Anxiety}

Technology anxiety is a common issue hampering the elderly's adoption of technology (Vroman, Arthanat, \& Lysack, 2015). Technology anxiety refers to users' apprehension when faced with the possibility of using new technologies (Simonson, Maurer, Montag-Torardi, \& Whitaker, 1987). In the elderly, it is often associated with self-imposed barriers, low self-efficacy in IT skills leading to the fear of technology, lack of interest, and lack of motivation (Marquié, Jourdan-Boddaert, \& Huet, 2002; Turner et al., 2007). Thus, technology anxiety negatively impacts the elderly's perception of their ability and willingness to use a technology (Meuter, Ostrom, Bitner, \& Roundtree, 2003). Even though technology anxiety has been researched extensively in psychology, its role as a determinant of individual attitudes in the context of $\mathrm{m}$-Government service adoption has not been investigated yet. Based on prior research (Guo et al., 2013; Phang et al., 2006), and our assumption that the elderly are more anxious regarding the extent of the effort needed to use $\mathrm{m}$-Government services, we postulate the following hypothesis:

H7: Technology anxiety (TA) has a negative impact on effort expectancy towards intention to use m-Government services.

\subsubsection{Declining Physiological Conditions}

The concept of declining physiological conditions refers to reduction in the state of bodily functions such as hearing, speech, locomotion, and memory capabilities (Phang et al., 2006). Research has shown that as physiological capabilities decline with age, the elderly are less able to perform information processing tasks (Birren, Woods, \& Williams, 1980) and allocate attention to information on the job (Plude \& Hoyer, 1985), both of which may be necessary when using IT services (Venkatesh et al., 2003) such as m-Government. As their physiological condition is declining, the elderly may perceive the use of the $\mathrm{m}$-Government services as more demanding effort-wise. Hence, declining physiological conditions can serve as internal controls or inhibiting conditions that decrease effort expectancy when using $\mathrm{m}$-Government services. Therefore, the following hypothesis is proposed:

H8: Declining physiological conditions (DPC) have a negative impact on effort expectancy towards the intention to use m-Government services. 


\subsubsection{Control Variables}

Two control variables are also included in the basic model to account for individual difference variables, namely experience with $\mathrm{m}$-Government systems and gender. Experience with $\mathrm{m}$-Government systems is defined as the degree of a person's direct and indirect experience with m-Government (Liu et al., 2014). While experience with existing technologies (such as m-Government) is generally high (as most users either have direct experience of using m-Government services or indirect experience by observing peers using them), more variation is expected among new technologies. Therefore, including familiarity as a control variable can parcel out variations in acceptance based on differences in knowledge about the technology. In addition, gender has been shown to relate to technology usage and represent common control variables in related research (Bao, Xiong, Hu, \& Kibelloh, 2013).

\section{METHODOLOGY}

\subsection{Measurement Instruments}

To ensure the validity of all constructs, measurement items for latent variables in the proposed model were developed based on prior studies (Al-Hujran, Al-Debei, Chatfield, \& Migdadi, 2015). The items of each construct and their sources are listed in Appendix A.

\subsection{Questionnaire Design and Data Collection}

A structured questionnaire was originally developed in English, and then translated into the local language (Bangla) by a professional translator. This is because most elderly in Bangladesh do not understand English, and they can only speak or write in Bangla. Next, the questionnaire was translated back into English by another professional translator. Based on this double translation process (Marin \& Marin, 1991), slight corrections were made to the questionnaire to ensure that the meanings of all items remained the same during translation. Two Bangladeshi academics with an excellent command of the English language and good knowledge of m-Government were asked to review the survey questionnaires in both languages for clarity of instructions, content validity, and consistency before a pilot study was conducted. Then, some items were reworded to improve readability and comprehension. This translation process is important for capturing the actual perception of the elderly population in Bangladesh (Hoque \& Sorwar, 2017). The finalized questionnaire has two parts: Parts A and B. Part A contains the demographic information regarding respondents' age, gender, educational qualifications, and mobile phone usage experience. Part B includes questions for the different constructs included in the proposed research model, shown in Figure 1, using a 5-point Likert scale ranging from (1) "strongly disagree" to (5) "strongly agree" (Luck \& Rubin, 1987; Premkumar \& Ramamurthy, 1995).

The first stage of the research involved a pilot study, which was conducted with 20 individuals randomly selected from among the retired government officers in Dhaka to test the appropriateness of the questionnaire. They were selected because they are 60 years or older and have mobile/Internet usage knowledge and experience. After they agreed to participate in the survey, they were given a demonstration of various m-Government services (e.g., money transfer, bill payment, and doctor's appointment, among others). Prior studies suggested that the initial interest towards IT services can be determined by providing such demonstration (Venkatesh, Sykes, \& Venkatraman, 2014). Intentions in such situations have been revealed to be symptomatic of future behavioral intention and use of IT services (Davis et al., 1989).

Feedback from the pilot study was used to adjust the questionnaire for the specific context of this study. Specifically, negatively worded items confused some participants (e.g., "Problems in my hearing, speech, moving, and memory limit the kind of activities that I can perform"). To reduce confusion, such items was rephrased accordingly. With older people as respondents, this issue seems to be more noticeable due to their cognitive limitations. Furthermore, some respondents also complained about similarly phrased items, as they found them boring and time-consuming to 
respond to. In response to their concerns, similarly phrased items were deleted on the condition that such deletion would not affect the content validity of the scales. Once more, such feedback revealed cognitive limitations that appear to be more relevant for senior citizens and need to be considered when designing questionnaires for the elderly.

In addition, some of the respondents complained that the fonts in the questionnaire as well as the mobile phone display were too small for them to read owing to their declining vision. Vision impairment has been associated with lower likelihood of technology use (Gell, Rosenberg, Demiris, LaCroix, \& Patel, 2013). In response, the questionnaire's font size was appropriately increased. However, this limitation remained on the mobile phone display and its small font size is therefore a continued hindrance to the ease of use of such services by the elderly.

In the second stage of the research, the revised questionnaire was given to 320 elderly persons - 40 each from eight divisional cities of Bangladesh. With the permission of local government authorities, participants were randomly selected at hospitals, parks, and homes. The respondents and their families were provided information about $\mathrm{m}$-Government services and the purpose of the study. Participation was completely voluntary, and respondents were also made aware of their rights to withdraw participation at any time during the study. Questionnaires were completed either by the respondents or by the data collectors on their behalf. Though home and location-based surveys are more time consuming and costly, they provide a higher response rate than other instruments (such as telephone or online surveys) in a developing country (Malhotra, 2008). Data was collected over a three-month period, from April 2017 to June 2017. In total, 320 questionnaires were returned; however, 26 were discarded due to invalid or incomplete responses providing us 294 valid responses for further analysis.

\subsection{Data Analysis}

The Partial Least Squares (PLS) method, a statistical analysis technique based on Structural Equation Modeling (SEM), was used to test and validate the proposed model and the relationships among the hypotheses in the research model (Chin, 1998). SEM is widely used to measure the validity of theories with empirical data (Götz, Liehr-Gobbers, \& Krafft, 2010). In this study, we used SmartPLS 3.2.6 software for statistical analysis (Ringle, Wende, \& Becker, 2015). The measurement items used in the analysis are described in Appendix A.

\section{RESULTS}

\subsection{Demographic Profile of Respondents}

The demographic characteristics of the respondents as shown in Appendix B indicate that, of the 294 respondents, there are 188 males and 106 females. Most of the respondents (53\%) are aged between 60 and 65 years, and 39\% of the respondents have attained at least a HSC (Higher Secondary Certificate equivalent to year 12) level education. In terms of access, $91 \%$ of the respondents have owned a mobile phone, and $60 \%$ of them have more than 4 years of mobile phone usage experience.

\subsection{Measurement Model}

The measurement model was assessed by examining the internal reliability, convergent validity, and discriminant validity criteria (Hair Jr, Hult, Ringle, \& Sarstedt, 2013). First, Cronbach's alpha and composite reliability (CR) were used to assess internal reliability of the constructs. The value of Cronbach's alpha and CR of each construct should exceed 0.70 to confirm internal reliability of the study (Hair, Anderson, Tatham, \& Black, 2006). As shown in Table 1, the Cronbach's alpha values obtained range from 0.756 to 0.856 , and $\mathrm{CR}$ values range from 0.851 to 0.913 , which support strong internal reliability. 
Next, the average variance extracted (AVE) and item loadings were used to assess convergent validity (Fornell \& Larcker, 1981). The AVE and item loading values must be at least 0.50 to meet the convergent validity (Fornell \& Larcker, 1981). As can be seen from Table 1, the calculated item loadings range from 0.714 to 0.908 , and AVE values range from 0.588 to 0.777 , all of which are greater than the recommended threshold. Therefore, the conditions of convergent validity of the measurement instruments are satisfied in this study.

Table 1. Results of the measurement model

\begin{tabular}{|c|c|c|c|c|c|}
\hline Construct & Items & Loadings & $\begin{array}{l}\text { Cronbach's } \\
\text { Alpha }\end{array}$ & CR & AVE \\
\hline \multirow{3}{*}{$\begin{array}{l}\text { Behavioral } \\
\text { Intension }\end{array}$} & BI1 & 0.852 & \multirow{3}{*}{0.856} & \multirow{3}{*}{0.913} & \multirow{3}{*}{0.777} \\
\hline & BI2 & 0.883 & & & \\
\hline & $\mathrm{BI} 3$ & 0.908 & & & \\
\hline \multirow{3}{*}{$\begin{array}{l}\text { Declining } \\
\text { Physiological } \\
\text { Conditions }\end{array}$} & DPC1 & 0.875 & \multirow{3}{*}{0.838} & \multirow{3}{*}{0.902} & \multirow{3}{*}{0.755} \\
\hline & DPC2 & 0.872 & & & \\
\hline & DPC3 & 0.859 & & & \\
\hline \multirow{4}{*}{$\begin{array}{l}\text { Effort } \\
\text { Expectancy }\end{array}$} & EE1 & 0.791 & \multirow{4}{*}{0.767} & \multirow{4}{*}{0.851} & \multirow{4}{*}{0.588} \\
\hline & EE2 & 0.769 & & & \\
\hline & EE3 & 0.791 & & & \\
\hline & EE4 & 0.714 & & & \\
\hline \multirow{3}{*}{$\begin{array}{l}\text { Facilitating } \\
\text { Conditions }\end{array}$} & $\mathrm{FC} 1$ & 0.821 & \multirow{3}{*}{0.776} & \multirow{3}{*}{0.87} & \multirow{3}{*}{0.691} \\
\hline & $\mathrm{FC} 2$ & 0.866 & & & \\
\hline & $\mathrm{FC} 3$ & 0.805 & & & \\
\hline \multirow{4}{*}{$\begin{array}{l}\text { Performance } \\
\text { Expectancy }\end{array}$} & PE1 & 0.85 & \multirow{4}{*}{0.85} & \multirow{4}{*}{0.899} & \multirow{4}{*}{0.69} \\
\hline & PE2 & 0.789 & & & \\
\hline & PE3 & 0.829 & & & \\
\hline & $\mathrm{PE} 4$ & 0.854 & & & \\
\hline \multirow{3}{*}{$\begin{array}{l}\text { Resistance to } \\
\text { Change }\end{array}$} & $\mathrm{RC} 1$ & 0.842 & \multirow{3}{*}{0.801} & \multirow{3}{*}{0.883} & \multirow{3}{*}{0.715} \\
\hline & $\mathrm{RC} 2$ & 0.881 & & & \\
\hline & $\mathrm{RC} 3$ & 0.813 & & & \\
\hline \multirow{3}{*}{ Self-actualization } & SA1 & 0.816 & \multirow{3}{*}{0.756} & \multirow{3}{*}{0.857} & \multirow{3}{*}{0.667} \\
\hline & SA2 & 0.777 & & & \\
\hline & SA3 & 0.855 & & & \\
\hline \multirow{3}{*}{ Social Influence } & SI1 & 0.874 & \multirow{3}{*}{0.776} & \multirow{3}{*}{0.87} & \\
\hline & SI2 & 0.843 & & & 0.692 \\
\hline & SI3 & 0.774 & & & \\
\hline & TA1 & 0.795 & & & \\
\hline Technology & $\mathrm{TA} 2$ & 0.834 & 0821 & 088 & 065 \\
\hline Anxiety & TA3 & 0.81 & 0.021 & 0.001 & 0.05 \\
\hline & TA4 & 0.785 & & & \\
\hline
\end{tabular}


Lastly, the discriminant validity was assessed by the square root of the AVE and cross-loading matrix as well as the Heterotrait-Monotrait ratio (Henseler, Ringle, \& Sarstedt, 2015). As can be seen in Table 2, the square root of the AVE of each construct is greater than its correlation with other constructs. This confirms that the discriminant validity of the data is satisfied (Henseler et al., 2015). The Heterotrait-Monotrait ratio is the ratio of the averages of correlations of the indicators across constructs and correlations of the indicators within the same construct (Henseler et al., 2015). The relevant literature suggests a maximum threshold of 0.9. Table 3 shows that all constructs have a value below the threshold, and thus the acceptance of discriminant validity.

Table 2. Results of the correlation matrix and square root of the AVE and VIF

\begin{tabular}{|l|l|l|l|l|l|l|l|l|l|}
\hline & \multicolumn{1}{|c|}{ BI } & \multicolumn{1}{|c|}{ DPC } & \multicolumn{1}{|c|}{ EE } & FC & PE & RC & SA & SI & TA \\
\hline BI & $\mathbf{0 . 8 8 2}$ & - & 1.714 & 1.439 & 1.714 & 1.550 & & 1.576 & \\
\hline DPC & 0.676 & $\mathbf{0 . 8 6 9}$ & 1.350 & & & & & & \\
\hline EE & 0.580 & 0.563 & $\mathbf{0 . 7 6 7}$ & - & & & & & 1.350 \\
\hline FC & 0.457 & 0.443 & 0.433 & $\mathbf{0 . 8 3 1}$ & - & & & & \\
\hline PE & 0.644 & 0.591 & 0.528 & 0.380 & $\mathbf{0 . 8 3 1}$ & - & 1.000 & & \\
\hline RC & 0.523 & 0.484 & 0.523 & 0.309 & 0.509 & $\mathbf{0 . 8 4 6}$ & - & & \\
\hline SA & 0.431 & 0.430 & 0.536 & 0.394 & 0.415 & 0.358 & $\mathbf{0 . 8 1 6}$ & - & \\
\hline SI & 0.421 & 0.423 & 0.431 & 0.490 & 0.492 & 0.373 & 0.336 & $\mathbf{0 . 8 3 2}$ & - \\
\hline TA & 0.555 & 0.509 & 0.454 & 0.496 & 0.501 & 0.487 & 0.382 & 0.495 & $\mathbf{0 . 8 0 6}$ \\
\hline
\end{tabular}

Note: Diagonal elements are the square root of AVE; these should exceed the inter-construct correlations for adequate discriminant validity. Values above diagonal elements are VIF values. Off-diagonal elements are the correlations among constructs

Table 3. Results of the Heterotrait-Monotrait ratio

\begin{tabular}{|l|l|l|l|l|l|l|l|l|}
\hline & BI & DPC & EE & FC & PE & RC & SA & SI \\
\hline DPC & 0.799 & & & & & & & \\
\hline EE & 0.708 & 0.699 & & & & & & \\
\hline FC & 0.56 & 0.547 & 0.559 & & & & & \\
\hline PE & 0.752 & 0.699 & 0.651 & 0.467 & & & & \\
\hline RC & 0.63 & 0.589 & 0.662 & 0.391 & 0.614 & & & \\
\hline SA & 0.523 & 0.538 & 0.684 & 0.518 & 0.497 & 0.462 & & \\
\hline SI & 0.513 & 0.523 & 0.555 & 0.627 & 0.596 & 0.467 & 0.443 & \\
\hline TA & 0.66 & 0.614 & 0.569 & 0.624 & 0.596 & 0.599 & 0.489 & 0.621 \\
\hline
\end{tabular}

Note: $\mathrm{BI}=$ Behavioral Intention; $\mathrm{PE}=$ Performance Expectancy; $\mathrm{EE}=$ Effort Expectancy; $\mathrm{SI}=$ Social Influence; $\mathrm{FC}=$ Facilitating Conditions; $\mathrm{TA}=\mathrm{Technology}$ Anxiety; RC= Resistance to Change; SA= Self-actualization; DPC= Declining Physiological Conditions

\subsection{Common Method Bias Testing}

We used several methods to test the common method bias (CMB). In Harman's one-factor test, if a single factor emerges or one general factor explains the majority of the variance, then there is a high level of common method variance (Podsakoff, MacKenzie, Lee, \& Podsakoff, 2003). The principal component factor analysis generated four factors; the highest variance explained by one 
factor accounted for $36.89 \%$, which is below the cutoff value (50\%) under Harman's single factor test (Chang, Wong, Libaque-Saenz, \& Lee, 2018). Due to the growing dispute regarding the merits of Harman's single-factor test (Lowry \& Gaskin, 2014), we re-validated CMB using other approaches. First, following Bagozzi, Yi, and Phillips (1991), we examined the correlation matrix of the constructs (Table 2) in the measurement instrument and found that there is no correlation greater than 0.90 . Second, if all the variance inflation factors (VIFs) resulting from a full collinearity test are less than or equal to 3.3, the model can be considered free of CMB (Kock \& Lynn, 2012; Ned, 2015). In this study, all the VIFs (see Table 2) are lower than 3.3. Using these approaches, we have concluded that the presence of the common method bias is an insignificant threat for our sample.

\subsection{Hypothesis Testing}

A structural model was constructed to identify the path relationships among the constructs of the research model. A bootstrapping method was used to test both the path coefficients and hypotheses at a significance level of $0.05(p<0.05)$. The relationships between dependent and independent variables were tested by path coefficient $(\beta)$ and t-statistics with values above 1.96 at 5\% significance level (Hair, Sarstedt, Ringle, \& Mena, 2012). The R square value was used to calculate the percentage of the variance explained by independent variables in the structural model (Klarner, Sarstedt, Hoeck, \& Ringle, 2013).

Results in Table 4 show that the relationships between PE and BI (PE: $t=5.938, \beta=0.380$ ), $\mathrm{EE}$ and $\mathrm{BI}(\mathrm{EE}: t=3.586, \beta=0.222), \mathrm{FC}$ and $\mathrm{BI}(\mathrm{FC}: t=2.973, \beta=0.171)$, RC and BI (RC: $t=$ $3.006, \beta=0.162$ ), SA and PE (SA: $t=7.694, \beta=0.422)$, TA and EE (TA: $t=4.056, \beta=0.229$ ), and DPC and EE (DPC: $t=8.059, \beta=0.449$ ) are significant, because the corresponding $t$-values of all the hypothesized relationships are above the recommended threshold of $5 \%$ significance level. Thus, H1, H2, H4, H5, H6, H7, and H8 are supported. However, the relationship between SI and BI (SI: $t=0.111, \beta=-0.003$ ) is insignificant due to the $\mathrm{t}$-value being below the recommended value of 1.96 at $5 \%$ level of significance. Therefore, H3 is not supported. None of the control variables are significantly related to intention, but they had some influence on behavioral intention (see Figure 2).

Table 4. Results of the structural model

\begin{tabular}{|l|l|l|l|l|}
\hline \multicolumn{1}{|c|}{ Hypothesis } & \multicolumn{1}{c|}{ Path } & \multicolumn{1}{c|}{ Coefficient $(\boldsymbol{\beta})$} & \multicolumn{1}{c|}{ t-value } & \multicolumn{1}{c|}{ Decision } \\
\hline H1 & PE -> BI & 0.380 & 5.938 & Supported \\
\hline H2 & EE -> BI & 0.222 & 3.586 & Supported \\
\hline H3 & SI -> BI & -0.003 & 0.111 & Not Supported \\
\hline H4 & FC -> BI & 0.171 & 2.973 & Supported \\
\hline H5 & SA -> PE & 0.422 & 7.694 & Supported \\
\hline H6 & RC -> BI & -0.162 & 3.006 & Supported \\
\hline H7 & TA -> EE & -0.229 & 4.056 & Supported \\
\hline H8 & DPC -> EE & -0.449 & 8.059 & Supported \\
\hline
\end{tabular}

$\mathrm{R}^{2}$ for $\mathrm{BI}=0.539$; Significant at $\mathrm{p}<0.05$.

This study also assessed effect sizes $\left(\mathrm{f}^{2}\right)$. Effect size $\mathrm{f}^{2}$ determines whether an exogenous latent construct has a substantial, moderate or weak impact on an endogenous latent construct (Gefen \& Pavlou, 2011). Cohen (1988) suggested as a guideline measure: a magnitude of $\mathrm{f}^{2}$ at 0.35 (large effects), 0.15 (medium effects) and 0.02 (small effects). The result of $\mathrm{f}^{2}$, as seen in Table 5, shows that the effect size for effort expectancy and performance expectancy on behavioral intention is medium. 
Using the blindfolding procedure, this study also examined the power of the proposed research model regarding predictive relevance. If the value of $\mathrm{Q}^{2}$ is greater than 0 , then the predictive relevance of the proposed model exists for a certain endogenous construct (Hair, Hult, Ringle, \& Sarstedt, 2016). The obtained $\mathrm{Q}^{2}$ values (see Table 5), after running the blindfolding procedure (Chin, 1998) with an omission distance $\mathrm{D}=7$, are well above zero; indicating the predictive relevance of the PLS path model.

Table 5. Results of $R^{2}, Q^{2}$, and $f^{2}$

\begin{tabular}{|l|l|l|l|}
\hline \multicolumn{1}{|c|}{ Endogenous latent variables } & \multicolumn{1}{c|}{$\mathbf{R}^{2}$} & \multicolumn{1}{c|}{$\mathbf{Q}^{2}$} & \multicolumn{1}{c|}{$\mathbf{f}^{2}$} \\
\hline Effort Expectancy & 0.373 & 0.215 & 0.231 \\
\hline Performance Expectancy & 0.181 & 0.121 & 0.225 \\
\hline Behavioral Intention & 0.539 & 0.400 & - \\
\hline
\end{tabular}

Figure 2. Partial least squares (PLS) results of the structural model with control variables. Note: ${ }^{*}=$ Significant at $P<0.05$; ${ }^{* *}=$ Significant at $P<0.01$. The numbers along the arrows refer to the coefficient values.

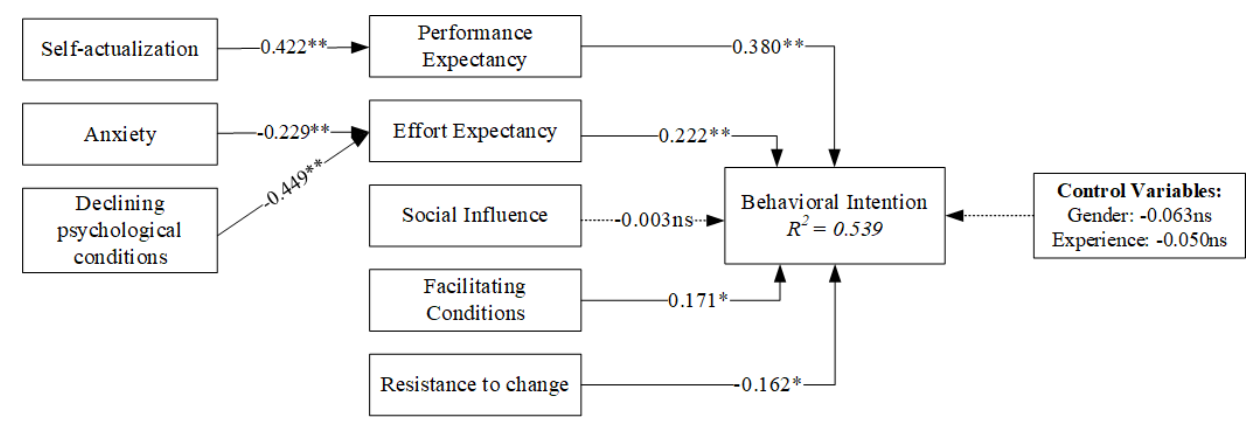

\section{DISCUSSION AND CONCLUSION}

\subsection{Discussion}

Government services depend greatly on mobile and other online technology platforms to reach elderly residents and achieve greater participation and deeper engagement. This study applied the dual factor model where the constructs of the UTAUT model and self-actualization are applied as enablers, while users' resistance to change, technology anxiety, and declining physiological conditions are considered as inhibitors to determine the elderly users' intention to use the m-Government services. The empirical findings have provided insight into the enablers and inhibitors, which have direct and indirect influence towards the adoption of $\mathrm{m}$-Government services, allowing us to expand the understanding of the difference in adoption among the elderly. Several key findings can be derived from the study.

The significant influence of performance expectancy and effort expectancy on behavioral intention point out that the elderly's intention to use m-Government services is influenced by their expectation of usefulness (i.e., greater performance) and ease of use (i.e., less complex). We also found facilitating conditions to be a direct determinant of behavioral intention. This result indicates that the elderly's intention to use m-Government services is influenced by arranging training programs, providing organizational and technological infrastructures, and making relevant resources available for them. These results are consistent with previous studies, which demonstrated that presence of performance expectancy, effort expectancy, and facilitating conditions are considered 
as vital enablers for the adoption of mobile-based system or technology by the elderly (Ahmad \& Khalid, 2017; Hoque \& Sorwar, 2017).

We found an unexpected but interesting point that the relationship between social influence and behavioral intention was insignificant for the use of $\mathrm{m}$-Government services by the elderly. It indicates that elderly people in Bangladesh seem to be least interested in recommending usage of $\mathrm{m}$-Government services to their relatives and friends. According to modernization theory (Cowgill \& Holmes, 1972), today's modernized and scientific society can trigger a loss of social status for the elderly because knowledge from the book is now valued more than knowledge acquired through personal experience (Brown, 1996). The elderly tend to disregard the influence of societal pressure, image, and social status and tend to pursue more emotionally meaningful goals (Carstensen, Fung, Charles, \& Emotion, 2003). Therefore, elderly people no longer put too much importance on their previous habits, and they are ready to change their styles of receiving m-Government services if necessary. The other root cause may be related to needs for privacy and data integrity. The social environment can be perceived as a potential threat (revealing personal information to close family members, colleagues, or peers). Additionally, this finding is consistent with some of the previous results reported in different information systems domains (Cimperman, Brenčič, \& Trkman, 2016; Sharma, Al-Badi, Rana, \& Al-Azizi, 2018).

We also observed that the need for self-actualization has a positive influence on performance expectancy towards behavioral intention to use m-Government services. According to Maslow et al. (1970), the ego integrity or self-actualization need is salient in later adulthood (the elderly). Higher level of self-actualization motivates the elderly to learn new skills and to use new technologies like m-Government (Heylighen, 1992). Adopting new IT services will become critical for successful adjustment to old age (Agarwal \& Prasad, 1998; Ahmed, Hossain, \& Chowdhury, 2009). Therefore, self-actualization increases the usage of systems like e-government, e-health, and m-Government (Phang et al., 2006), and the results of this research support that proposition.

Along with the enablers, the study also identified that resistance to change has a significant but negative influence on the elderly's intention to use m-Government services. According to the continuity theory (Atchley, 1989), we observed that the elderly would prefer the traditional channels to access public services based on their previous experiences. Compared to developed countries, most of the elderly in Bangladesh usually prefer face-to-face transactions rather than innovative IT-based services like m-Government (Ahmed et al., 2014). The reason for this might be the inequalities and inconvenience of accessing government services, particularly for the elderly. They probably do not want to change to a small screen mobile device to obtain health services. Thus, the perception of resistance to change will negatively affect their adoption of mobile health services.

Among the proposed antecedents of perceived ease of use, support was found for technology anxiety and declining physiological conditions. The probable reason is that most elderly people have retired; they are less familiar with technology, and thus their perceptions of technology anxiety are stronger. They would hence be more likely not to use $\mathrm{m}$-Government services. The finding is consistent with previous research, which found that technology anxiety could reduce the adoption intention of elderly by reducing the effort expectancy (ease of use) (Guo et al., 2013; Phang et al., 2006). In addition, declining physiological conditions (i.e., decline in hearing, vision, speech, and memory) of the elderly suggest that more effort is needed, and more difficulties are experienced when they attempt to use m-Government services. More specifically, in Bangladesh, Hoque and Sorwar (2017) found that $72 \%$ of the elderly have suffered at least one age-related chronic disease, which reduces their physical and mental capabilities to use new technologies.

To sum up, the findings confirm that the aging-specific variables (RC, TA, and DPC) are proven as critical constructs in innovation adoption studies among the elderly. The proposed model could explain $41.4 \%$ of the variance in intention to use and increased to $53.9 \%$ on inclusion of aforementioned additional contextual constructs. Therefore, inclusion of additional constructs has increased predictive power of the proposed research model. 


\subsection{Theoretical Implications}

This is one of the first studies to empirically validate Cenfetelli's (2004) dual factor model of IT usage in the m-Government service context. The dual-factor model can shed light on both the bright and dark sides of technology acceptance behaviour (Guo et al., 2013). More specifically, the UTAUT variables and self-actualization are identified as the enablers; and resistance to change, technology anxiety, and declining physiological conditions are regarded as the inhibitors. When examining the effects of the enablers and the inhibitors, we found that the enablers and inhibitors both have a direct influence on m-Government services adoption intention, and that indirect influence on behavioural intention is fully mediated by performance expectancy and effort expectancy. Future research on technology acceptance should include the inhibitors as important predictors of behavioural intention by drawing upon the dual factor model and pay special attention to the mediating effects of enablers.

In addition, we empirically validated the constructs of the UTAUT model as enablers to determine behavioral intention to use m-Government services by the elderly. By doing so, the present research contributes to the existing literature on innovation adoption and behavioral intention. The specified behavioral model is very appropriate in this context. The results indicate that people do not necessarily demonstrate the same type of adoption behavior when new services are introduced. This means that factors that either facilitate or inhibit innovative services are not the same and their effect is not consistent. Even among the elderly, there are possibly several diverging segments in which the behavior has different features. The findings can stimulate digital divide research, and research concerned with age-related aspects in particular. We contribute constructs to digital divide research, which represent traits and beliefs and exert a significant influence on IT adoption.

\subsection{Methodological Implications}

Apart from these theoretical implications, this study highlighted the need to cater to the growing population of the elderly as they will be one of the most obvious groups of m-Government users in years to come. As an initial research endeavor on elderly acceptance of $\mathrm{m}$-Government services, this study can contribute to future research as well as the practice of providing $\mathrm{m}$-Government services for the elderly.

Specifically, the study shed light on how survey instruments can be considered to accommodate the reduced cognitive capabilities of the elderly. First, inverse phrased items may be confusing for this group and should be avoided. Second, similarly phrased items added for reliability may prove onerous for elderly. Hence, a balance needs to be struck between reliability requirements and the elderly's cognitive load. Lastly, instrument length considerations are particularly heightened for the elderly. Thus, the length of the survey questionnaire must be kept manageable for the elderly, even more so than for younger age groups.

\subsection{Practical Implications}

From a practical point of view, the findings of this study reveal the important role of the following constructs: performance expectancy, effort expectancy, facilitating conditions, self-actualization, resistance to change, technology anxiety, declining physiological conditions, and behavioral intention. Therefore, we recommend that these constructs are given special consideration while developing mobile applications for citizen-centric services. In addition, the government agencies can correlate these findings while they are planning to develop and implement similar projects in other domains. Due to a generic approach, the results of the study will help in the development of suitable strategies and policies for attracting more residents to use m-Government services in the context of any developing country.

We found performance expectancy and effort expectancy to be the antecedents of behavioral intention. This implies that individuals attribute substantial importance to the technological extent to which m-Government services are useful and easy to use. Therefore, designers, system analysts, 
and developers responsible for the design and development of $\mathrm{m}$-Government systems should focus more on minimizing the complexities associated with exploration and use of the system, if any, and maximizing the usefulness of the system, such that the acceptance and use of such systems may be managed more successfully. This result also validates the significant impact of declining physiological conditions on effort expectancy by the elderly. Possible ways of achieving these objectives may include the use of large font sizes, contrasting colors, voice assistive service, and placement of icons at easy-to-see locations while developing m-Government applications for the elderly.

The results also highlight the significant relationship between facilitating conditions and behavioral intentions. It implies that elderly residents place substantial importance on facilities provided by government to utilize government services on mobile devices. The government should develop short training programs about appropriate usage of facilities through public and private institutions to users at regular intervals across the country. Such services would not only help new and potential users learn about government services on mobile devices but also make them familiar with upcoming services.

The result validates that elderly have a higher need for self-actualization. This need can be fulfilled through the process of learning and using newer technologies. Consequently, service providers should design a user-friendly interface and provide a more accessible and complete help menu or design a special mode with additional functions (i.e., voice prompt) for the elderly, thus helping them to enjoy the process of using $\mathrm{m}$-Government services.

Among the inhibitors, technology anxiety has significant negative effects on the adoption behavior of older users. Therefore, providers should undertake measures, such as providing good illustrations and training, to ease the use of the service and eliminate older users' anxiety about the technology. We also observed the significant but negative relationship between resistance to change and behavioral intentions by the elderly. This indicates that providers should also persuade the elderly that m-Government services would simplify their lives and demonstrate how the service will help ease the management of their work. Furthermore, due to a generic approach, the findings of this study could be adopted to assist other developing countries in the planning and uptake of $\mathrm{m}$-Government services for the elderly.

\subsection{Limitations and Future Directions}

The study has some limitations. First, due to the cross-sectional design, the proposed study cannot confirm the causality and conditional effects of users' level of experience before and after the m-Government service adoption. It is also known that cross-sectional data might not provide an exact prediction of behavioral intention of technology use. Future work may use longitudinal data to explain the causal relationship among variables over time. Second, this study mainly focused on the general perception of elderly regarding $\mathrm{m}$-Government service adoption instead of a particular type of service. Future research may focus on a specific service type like mobile money transfer or $\mathrm{m}$-ticketing to overcome this limitation. Another extension could be to adopt both quantitative and qualitative approaches to understand users' in-depth views and/or opinions on the issues.

\subsection{Conclusion}

The turn of the century has seen a rapidly graying population as well as increasingly ubiquitous information and communication technologies. The relatively less familiarity of the older population with IT implies that issues pertaining to their acceptance of IS deserve special attention. However, empirical studies on this issue are rarely conducted from the elderly users' perspective. Attempting to address this gap, an integrated research model based on the dual factor model was proposed, where the constructs of the UTAUT model and self-actualization were treated as enablers, while resistance to change, technology anxiety, and declining physiological conditions were applied as inhibitors.

The study found that performance expectancy, effort expectancy, facilitating conditions, resistance to change, technology anxiety, self-actualization, and declining physiological conditions significantly 
influence the elderly's behavioral intention to use m-Government services. Social influence was, however, found not to have a significant influence. This study also encourages future research on technology acceptance to focus on both enablers and inhibitors. Practitioners in this field should work towards determining the methods of removing the barriers caused by certain dispositional factors in order to facilitate the use of $\mathrm{m}$-Government services by the elderly.

\section{ACKNOWLEDGMENT}

This study was supported by the National Natural Science Foundation of China under Project No. 71810107003 . 


\section{REFERENCES}

Abdelghaffar, H., \& Magdy, Y. (2012). The adoption of mobile government services in developing countries: The case of Egypt. International Journal of Information, 2(4), 333-341.

Agarwal, R., \& Prasad, J. (1998). A conceptual and operational definition of personal innovativeness in the domain of information technology. Information Systems Research, 9(2), 204-215. doi:10.1287/isre.9.2.204

Ahmad, S. Z., \& Khalid, K. (2017). The adoption of M-government services from the user's perspectives: Empirical evidence from the United Arab Emirates. International Journal of Information Management, 37(5), 367-379. doi:10.1016/j.ijinfomgt.2017.03.008

Ahmed, S. M., Hossain, M. A., \& Chowdhury, M. R. (2009). Informal sector providers in Bangladesh: How equipped are they to provide rational health care? Health Policy and Planning. PMID:19720721

Ahmed, T., Bloom, G., Iqbal, M., Lucas, H., Rasheed, S., Waldman, L., \& Bhuiya, A. (2014). E-health and M-Health in Bangladesh: Opportunities and Challenges. IDS.

Al-Hadidi, A., \& Rezgui, Y. (2010). Adoption and diffusion of m-Government: Challenges and Future Directions for Research. In Collaborative Networks for a Sustainable World (pp. 88-94). Springer.

Al-Hubaishi, H. S., Al-Hubaishi, H. S., Ahmad, S. Z., Ahmad, S. Z., Hussain, M., \& Hussain, M. (2017). Exploring mobile government from the service quality perspective. Journal of Enterprise Information Management, 30(1), 4-16. doi:10.1108/JEIM-01-2016-0004

Al-Hujran, O., Al-Debei, M. M., Chatfield, A., \& Migdadi, M. (2015). The imperative of influencing citizen attitude toward e-government adoption and use. Computers in Human Behavior, 53, 189-203. doi:10.1016/j. chb.2015.06.025

Atchley, R. C. (1989). A Continuity Theory of Normal Aging. The Gerontologist, 29(2), 183-190. doi:10.1093/ geront/29.2.183 PMID:2519525

Bagozzi, R. P., Yi, Y., \& Phillips, L. W. (1991). Assessing Construct Validity in Organizational Research. Administrative Science Quarterly, 36(3), 421-458. doi:10.2307/2393203

Bao, Y., Hoque, R., \& Wang, S. (2017). Investigating the determinants of Chinese adult children's intention to use online health information for their aged parents. International Journal of Medical Informatics, 102, 12-20. doi:10.1016/j.ijmedinf.2017.01.003 PMID:28495340

Bao, Y., Xiong, T., Hu, Z., \& Kibelloh, M. (2013). Exploring gender differences on general and specific computer self-efficacy in mobile learning adoption. Journal of Educational Computing Research, 49(1), $111-132$. doi:10.2190/EC.49.1.e

Bangladesh Bureau of Statistics. (2017). Statistical pocketbook of Bangladesh. Dhaka, Bangladesh: Ministry of Planning.

Bhattacherjee, A., \& Hikmet, N. (2007). Physicians' resistance toward healthcare information technology: A theoretical model and empirical test. European Journal of Information Systems, 16(6), 725-737. doi:10.1057/ palgrave.ejis. 3000717

Birren, J. E., Woods, A. M., \& Williams, M. V. (1980). Behavioral slowing with age: Causes, organization, and consequences. In Aging in the 1980s: Psychological issues (pp. 293-308). Academic Press.

Brown, A. S. (1996). The social processes of aging and old age. New York: Prentice Hall Upper Saddle River.

Carstensen, L. L., Fung, H. H., \& Charles, S. T. J. M. (2003). Socioemotional Selectivity Theory and the Regulation of Emotion in the Second Half of Life. Motivation and emotion, 27(2), 103-123.

Cenfetelli, R. T. (2004). Inhibitors and enablers as dual factor concepts in technology usage. Journal of the Association for Information Systems, 5(11), 16. doi:10.17705/1jais.00059

Chang, Y., Wong, S. F., Libaque-Saenz, C. F., \& Lee, H. (2018). The role of privacy policy on consumers' perceived privacy. Government Information Quarterly, 35(3), 445-459. doi:10.1016/j.giq.2018.04.002 
Chin, W. W. (1998). The partial least squares approach to structural equation modeling. Modern methods for business research, 295(2), 295-336.

Chong, A. Y.-L., Darmawan, N., Ooi, K.-B., \& Lin, B. (2010). Adoption of 3G services among Malaysian consumers: An empirical analysis. International Journal of Mobile Communications, 8(2), 129-149. doi:10.1504/ IJMC.2010.031444

Choudrie, J., Alfalah, A., \& Spencer, N. (2017). Older Adults Adoption, Use and Diffusion of E-Government Services in Saudi Arabia, Hail City: A Quantitative Study. Paper presented at Hawaii International Conference on System Sciences 50th Anniversary. Academic Press.

Cimperman, M., Brenčič, M. M., \& Trkman, P. (2016). Analyzing older users' home telehealth services acceptance behavior-applying an Extended UTAUT model. International Journal of Medical Informatics, 90, 22-31. doi:10.1016/j.ijmedinf.2016.03.002 PMID:27103194

Cohen, J. (1988). Statistical Power Analysis for the Behavioral Sciences. New Jersey Lawrence Erlbaum Associates Inc. Publishers.

Conci, M., Pianesi, F., \& Zancanaro, M. (2009). Useful, social and enjoyable: Mobile phone adoption by older people. Paper presented at the IFIP Conference on Human-Computer Interaction. Academic Press. doi:10.1007/978-3-642-03655-2_7

Cowgill, D. O., \& Holmes, L. D. (1972). Aging and modernization. New York: Appleton-Century-Crofts and Fleschner Publishing Company.

Davis, F. (1989). Perceived usefulness, perceived ease of use, and user acceptance of information technology. Management Information Systems Quarterly, 13(3), 319-340. doi:10.2307/249008

Davis, F. D., Bagozzi, R. P., \& Warshaw, P. R. (1989). User acceptance of computer technology: A comparison of two theoretical models. Management Science, 35(8), 982-1003. doi:10.1287/mnsc.35.8.982

Deng, Z., Mo, X., \& Liu, S. (2014). Comparison of the middle-aged and older users' adoption of mobile health services in China. International Journal of Medical Informatics, 83(3), 210-224. doi:10.1016/j. ijmedinf.2013.12.002 PMID:24388129

Dwivedi, Y. K., Wastell, D., Laumer, S., Henriksen, H. Z., Myers, M. D., Bunker, D., \& Srivastava, S. C. et al. (2015). Research on information systems failures and successes: Status update and future directions. Information Systems Frontiers, 17(1), 143-157. doi:10.1007/s10796-014-9500-y

Fornell, C., \& Larcker, D. F. (1981). Evaluating Structural Equation Models with Unobservable Variables and Measurement Error. JMR, Journal of Marketing Research, 18(1), 39-50. doi:10.1177/002224378101800104

Gefen, D., \& Pavlou, P. A. (2011). The Boundaries of Trust and Risk: The Quadratic Moderating Role of Institutional Structures. Information systems research, 23(3 Part 2), 940-959.

Gell, N. M., Rosenberg, D. E., Demiris, G., LaCroix, A. Z., \& Patel, K. V. (2013). Patterns of technology use among older adults with and without disabilities. The Gerontologist, 55(3), 412-421. doi:10.1093/geront/gnt166 PMID:24379019

Götz, O., Liehr-Gobbers, K., \& Krafft, M. (2010). Evaluation of structural equation models using the partial least squares (PLS) approach. In Handbook of partial least squares (pp. 691-711). Springer.

Guo, X., Sun, Y., Wang, N., Peng, Z., \& Yan, Z. (2013). The dark side of elderly acceptance of preventive mobile health services in China. Electronic Markets, 23(1), 49-61. doi:10.1007/s12525-012-0112-4

Hair, J., Anderson, R., Tatham, R., \& Black, W. (2006). Multivariate data analysis (6th ed.). Prentice Hall.

Hair, J. F., Sarstedt, M., Ringle, C. M., \& Mena, J. A. (2012). An assessment of the use of partial least squares structural equation modeling in marketing research. Journal of the Academy of Marketing Science, 40(3), 414-433. doi:10.1007/s11747-011-0261-6

Hair, J. F. Jr, Hult, G. T. M., Ringle, C., \& Sarstedt, M. (2013). A primer on partial least squares structural equation modeling (PLS-SEM). New Jersey: Sage Publications. 
Hair, J. F. Jr, Hult, G. T. M., Ringle, C., \& Sarstedt, M. (2016). A primer on partial least squares structural equation modeling (PLS-SEM). Thousand Oaks: Sage Publications.

Henseler, J., Ringle, C. M., \& Sarstedt, M. (2015). A new criterion for assessing discriminant validity in variance-based structural equation modeling. Journal of the Academy of Marketing Science, 43(1), 115-135. doi:10.1007/s11747-014-0403-8

Heylighen, F. (1992). A cognitive-systemic reconstruction of maslow's theory of self-actualization. Behavioral Science, 37(1), 39-58. doi:10.1002/bs.3830370105

Hirschheim, R., \& Newman, M. (1988). Information systems and user resistance: Theory and practice. The Computer Journal, 31(5), 398-408. doi:10.1093/comjn1/31.5.398

Hoque, R., \& Sorwar, G. (2017). Understanding factors influencing the adoption of mHealth by the elderly: An extension of the UTAUT model. International Journal of Medical Informatics, 101, 75-84. doi:10.1016/j. ijmedinf.2017.02.002 PMID:28347450

Hung, S.-Y., Chang, C.-M., \& Kuo, S.-R. (2013). User acceptance of mobile e-government services: An empirical study. Government Information Quarterly, 30(1), 33-44. doi:10.1016/j.giq.2012.07.008

Hussain, M., \& Imran, A. (2015). Effects of Organizational Culture on M-Government Adoption: A Case Study on E-Purjee in Bangladesh. Paper presented at the PACIS 2015 Proceedings. Academic Press.

Ikram Ullah, K., Yugang, Y., Zahid, H., Safeer Ullah, K., \& Abdul, W. (2018). Assessing the Physicians' Acceptance of E-Prescribing in a Developing Country: An Extension of the UTAUT Model With Moderating Effect of Perceived Organizational Support. Journal of Global Information Management, 26(3), 121-142. doi:10.4018/JGIM.2018070109

Irani, Z., Elliman, T., \& Jackson, P. (2007). Electronic transformation of government in the UK: A research agenda. European Journal of Information Systems, 16(4), 327-335. doi:10.1057/palgrave.ejis.3000698

Klarner, P., Sarstedt, M., Hoeck, M., \& Ringle, C. M. (2013). Disentangling the Effects of Team Competences, Team Adaptability, and Client Communication on the Performance of Management Consulting Teams. Long Range Planning, 46(3), 258-286. doi:10.1016/j.lrp.2013.03.001

Kock, N., \& Lynn, G. (2012). Lateral Collinearity and Misleading Results in Variance-Based SEM: An Illustration and Recommendations. Journal of the Association for Information Systems, 13(7), 546-580. doi:10.17705/1jais.00302

Lallmahomed, M. Z., Lallmahomed, N., \& Lallmahomed, G. M. (2017). Factors influencing the adoption of e-Government services in Mauritius. Telematics and Informatics, 34(4), 57-72. doi:10.1016/j.tele.2017.01.003

Liu, Y., Li, H., Kostakos, V., Goncalves, J., Hosio, S., \& Hu, F. (2014). An empirical investigation of mobile government adoption in rural China: A case study in Zhejiang province. Government Information Quarterly, 31(3), 432-442. doi:10.1016/j.giq.2014.02.008

Lowry, P. B., \& Gaskin, J. (2014). Partial Least Squares (PLS) Structural Equation Modeling (SEM) for Building and Testing Behavioral Causal Theory: When to Choose It and How to Use It. IEEE Transactions on Professional Communication, 57(2), 123-146. doi:10.1109/TPC.2014.2312452

Luck, D., \& Rubin, R. (1987). Marketing research (7th ed.). New Jersey: Prentice-Hall International.

Malhotra, N. K. (2008). Marketing research: An applied orientation, 5/e. Pearson Education India. doi:10.1108/ S1548-6435(2008)4

Marin, G., \& Marin, B. V. (1991). Research with Hispanic populations. Sage Publications, Inc. doi: $10.4135 / 9781412985734$

Marquié, J. C., Jourdan-Boddaert, L., \& Huet, N. (2002). Do older adults underestimate their actual computer knowledge? Behaviour \& Information Technology, 21(4), 273-280. doi:10.1080/0144929021000020998

Maslow, A. H., Frager, R., Fadiman, J., McReynolds, C., \& Cox, R. (1970). Motivation and personality (Vol. 2). Harper \& Row New York. 
Meuter, M. L., Ostrom, A. L., Bitner, M. J., \& Roundtree, R. (2003). The influence of technology anxiety on consumer use and experiences with self-service technologies. Journal of Business Research, 56(11), 899-906. doi:10.1016/S0148-2963(01)00276-4

Ned, K. (2015). Common Method Bias in PLS-SEM: A Full Collinearity Assessment Approach. International Journal of e-Collaboration, 11(4), 1-10. doi:10.4018/ijec.2015100101

Phang, C. W., Sutanto, J., Kankanhalli, A., Li, Y., Tan, B. C. Y., \& Teo, H. H. (2006). Senior Citizens' Acceptance of Information Systems: A Study in the Context of e-Government Services. IEEE Transactions on Engineering Management, 53(4), 555-569. doi:10.1109/TEM.2006.883710

Plude, D. J., \& Hoyer, W. (1985). Attention and performance: Identifying and localizing age deficits. Aging and human performance, 47-99.

Podsakoff, P. M., MacKenzie, S. B., Lee, J.-Y., \& Podsakoff, N. P. (2003). Common method biases in behavioral research: A critical review of the literature and recommended remedies. The Journal of Applied Psychology, 88(5), 879-903. doi:10.1037/0021-9010.88.5.879 PMID:14516251

Premkumar, G., \& Ramamurthy, K. (1995). The role of interorganizational and organizational factors on the decision mode for adoption of interorganizational systems. Decision Sciences, 26(3), 303-336. doi:10.1111/j.1540-5915.1995.tb01431.x

Ringle, C. M., Wende, S., \& Becker, J.-M. (2015). SmartPLS 3. Boenningstedt: SmartPLS GmbH. http://www. smartpls.com

Saxena, S. (2017). Open public data (OPD) and the Gulf Cooperation Council (GCC): Challenges and prospects. Contemporary Arab Affairs, 10(2), 228-240. doi:10.1080/17550912.2017.1297565

Sharma, S. K., Al-Badi, A., Rana, N. P., \& Al-Azizi, L. (2018). Mobile applications in government services (mG-App) from user's perspectives: A predictive modelling approach. Government Information Quarterly, 35(4), 557-568. doi:10.1016/j.giq.2018.07.002

Simonson, M. R., Maurer, M., Montag-Torardi, M., \& Whitaker, M. (1987). Development of a standardized test of computer literacy and a computer anxiety index. Journal of Educational Computing Research, 3(2), $231-247$. doi:10.2190/7CHY-5CM0-4D00-6JCG

Sintonen, S., \& Immonen, M. (2013). Telecare services for aging people: Assessment of critical factors influencing the adoption intention. Computers in Human Behavior, 29(4), 1307-1317. doi:10.1016/j.chb.2013.01.037

Sultan, A.-O., Naif Radi, A., Md. Rakibul, H., \& Fahd, S. A. (2018). The Satisfaction of Saudi Customers Toward Mobile Banking in Saudi Arabia and the United Kingdom. Journal of Global Information Management, 26(1), 85-103. doi:10.4018/JGIM.2018010105

Susanto, T. D., \& Goodwin, R. (2011). User acceptance of SMS-based egovernment services. In electronic government (pp. 75-87). Springer. doi:10.1007/978-3-642-22878-0_7

Talukder, M. S., Chiong, R., Bao, Y., \& Hayat Malik, B. (2019). Acceptance and use predictors of fitness wearable technology and intention to recommend: An empirical study. Industrial Management \& Data Systems, 119(1), 170-188. doi:10.1108/IMDS-01-2018-0009

Talukder, M. S., Shen, L., Hossain Talukder, M. F., \& Bao, Y. (2019). Determinants of user acceptance and use of open government data (OGD): An empirical investigation in Bangladesh. Technology in Society, 56, $147-156$. doi:10.1016/j.techsoc.2018.09.013 
Shamim Talukder is currently an Assistant Professor of Management in North South University, Dhaka Bangladesh. He obtained his Ph.D. from the Huazhong University of Science and Technology, Wuhan, China. His teaching and research interests include structural equation modelling, neural network modelling, multivariate data analysis, technology acceptance, healthcare technology, and e-government. His research has been published in journals such as Industrial Management and Data Systems, Technology in Society, and Foresight. He serves as a reviewer for many peer review journals including Information Technology and People, and the Journal of Systems and Information Technology.

Raymond Chiong is a Senior Lecturer at the University of Newcastle, Australia. He is also a Guest Research Professor with the Center for Modern Information Management at Huazhong University of Science and Technology, China. He obtained his PhD from the University of Melbourne. His research interests include game theory, optimization, and data analytics. He is the Editor-in-Chief of the Journal of Systems and Information Technology, an Editor of Engineering Applications of Artificial Intelligence, and an Associate Editor of the IEEE Computational Intelligence Magazine. He has produced more than 140 refereed publications to date.

Brian Corbitt is an Emeritus Professor and Professor of Information Systems at RMIT University in Melbourne, Australia. Professor Corbitt specialized his research in Information Systems modelling, business policy and IT, ebusiness, eGovernment and spatial information systems. He is currently investigating the notion of 'place' in social structure and behavior, and policy sociology investigations of the impact of imposed macro policy across nations or within nations. He has published 10 books on eBusiness, eCommerce, and eGovernment. He has also published over 210 refereed scholarly papers.

Yukun Bao is currently a Professor at school of management, Huazhong University of Science and Technology, and a deputy director of Center for Modern Information Management, Huazhong University of Science and Technology. His research interests are computational intelligence based predictive analytics, medical informatics and educational informatics. He has been the PI for four projects funded by National Science Foundation of China and received Excellent Faculty Award from IBM in 2012. He is a councilor of the Chinese Association of Computer Simulation, senior member of IEEE and professional activity chair of IEEE Wuhan Section. He has served as Associate Editor of Neurocomputing (Elsevier) and the Journal of Systems and Information Technology (Emerald). 